Article

\title{
Effective Zearalenone Degradation in Model Solutions and Infected Wheat Grain Using a Novel Heterologous Lactonohydrolase Secreted by Recombinant Penicillium canescens
}

\author{
Larisa Shcherbakova $^{1, *}$, Alexandra Rozhkova ${ }^{2}\left(\mathbb{D}\right.$, Dmitrii Osipov $^{2}{ }^{(0)}$, Ivan Zorov ${ }^{2}$, \\ Oleg Mikityuk ${ }^{1}$, Natalia Statsyuk ${ }^{1, *(\mathbb{D}}$, Olga Sinitsyna ${ }^{3}$, Vitaly Dzhavakhiya ${ }^{1}$ and \\ Arkady Sinitsyn ${ }^{2,3}$ \\ 1 All-Russian Research Institute of Phytopathology, Bolshie Vyazemy, 143050 Moscow, Russia; \\ mod-39@list.ru (O.M.); dzhavakhiya@yahoo.com (V.D.) \\ 2 Federal Research Centre "Fundamentals of Biotechnology" of the Russian Academy of Sciences, \\ 119071 Moscow, Russia; a.rojkova@fbras.ru (A.R.); doosipov@gmail.com (D.O.); inzorov@mail.ru (I.Z.); \\ apsinitsyn@gmail.com (A.S.) \\ 3 Chemistry Department, M.V. Lomonosov Moscow State University, 119991 Moscow, Russia; \\ oasinitsyna@gmail.com \\ * Correspondence: larisavniif@yahoo.com (L.S.); nataafg@gmail.com (N.S.)
}

Received: 29 June 2020; Accepted: 23 July 2020; Published: 25 July 2020

\begin{abstract}
This paper reports the first results on obtaining an enzyme preparation that might be promising for the simultaneous decontamination of plant feeds contaminated with a polyketide fusariotoxin, zearalenone (ZEN), and enhancing the availability of their nutritional components. A novel ZEN-specific lactonohydrolase (ZHD) was expressed in a Penicillium canescens strain PCA-10 that was developed previously as a producer of different hydrolytic enzymes for feed biorefinery. The recombinant ZHD secreted by transformed fungal clones into culture liquid was shown to remove the toxin from model solutions, and was able to decontaminate wheat grain artificially infected with a zearalenone-producing Fusarium culmorum. The dynamics of ZEN degradation depending on the temperature and $\mathrm{pH}$ of the incubation media was investigated, and the optimal values of these parameters $\left(\mathrm{pH} 8.5,30^{\circ} \mathrm{C}\right)$ for the ZHD-containing enzyme preparation (PR-ZHD) were determined. Under these conditions, the $3 \mathrm{~h}$ co-incubation of ZEN and PR-ZHD resulted in a complete removal of the toxin from the model solutions, while the PR-ZHD addition $(8 \mathrm{mg} / \mathrm{g}$ of dried grain) to flour samples prepared from the infected ZEN-polluted grain (about $16 \mu \mathrm{g} / \mathrm{g}$ ) completely decontaminated the samples after an overnight exposure.
\end{abstract}

Keywords: zearalenone; decontamination; enzymatic degradation; lactonohydrolase; enzyme preparations; recombinant proteins; safe agricultural products; improving the feed nutritional value

Key Contribution: An enzyme preparation containing lactonohydrolase heterologously expressed by a $P$. canescens strain, a producer of extracellular enzymes cleaving poorly digested feed components, effectively degrades mycotoxin zearalenone and holds promise for the simultaneous decontamination of plant feeds and the improvement of the availability of their nutrients.

\section{Introduction}

For current high-productive agriculture, the provision of the safety of feedstuffs and the improvement of their nutritional value are important and interrelated challenges, which require 
an integrated approach. Several strategies were developed in recent decades to solve these problems including the enzymatic decontamination of mycotoxin-polluted agricultural feedstock, as well as the removal of anti-nutritional factors from silage, hay, fodder or other feeds, using enzyme preparations [1,2]. However, there is still a need in the development of new remedies with the involvement of innovative advances to promote the production of safe feeds possessing high nutritional value.

The toxicological safety of plant and livestock products is a prerequisite for food safety. Mycotoxins produced by Fusarium fungi belong to well known feed pollutants, which are able to enter the food chains and induce serious risks for human and animal health [3] as well as result in significant economic losses. One of the most common fusariotoxins, zearalenone (ZEN) [4,5], is synthesized through a polyketide pathway as a secondary metabolite in several common Fusarium species (e.g., F. culmorum, F. graminearum, and also F. avenaceum, F. poae, F. equiseti), which damage grain cereals, forage grasses, legumes, vegetables, and other economically significant crops in regions of temperate or warm climate including Russia [6-8]. These fungi keep growing on forage grasses and grain during storage, causing post-harvest contamination with ZEN [9]. This mycotoxin is highly thermostable, insensitive to UV irradiation, is not destroyed during feed or food processing, and remains toxic after all these exposures $[10,11]$. It can be broken chemically only in strong alkalis or oxidants, the use of which is quite limited because of the obvious drawbacks [12]. In contrast to steroid hormones, ZEN is a nonsteroidal compound (a macrocyclic lactone of $\beta$-resorcylic acid [13]), but possesses a high estrogenic activity, disrupts the functioning of reproductive and endocrine systems in humans and animals $[10,11]$, as well as suppresses the immunity $[14,15]$.

Since ZEN is a feed and food contaminant of a considerable concern, the development of methods for its effective detoxification, which would provide keeping the quality of the treated feedstuffs and minimally affect the environment, is of a special attention. A large cluster of such investigations is focused on ZEN transformation or degradation to non-estrogenic derivatives $[10,13]$ using microbes [16-20] or isolated enzymes [1,21-24], especially lactonase (lactonohydrolase) from Clonostachys rosea [25-27]. The enzyme ability to open the lactone ring in a toxin molecule and to deprive the ZEN of the estrogenic activity is well documented [19,28-30]. A number of studies, which describethe ZEN derivatives formed after the enzymatic reaction, as well as a zhd101 gene cloning and ZHD101 expression in some prokaryotes and eukaryotes [27,28,31,32], suggested that recombinant lactonohydrolases initially originated from $C$. rosea could be used as an efficient remedy for ZEN decontamination.

A few years ago, we showed that Clonostachys rosea (the former name Gliocladium roseum) strain GRZ7, produced extracellular metabolites destroying aflatoxin B1 [33], one of polyketide mycotoxins, the molecule of which contains the lactone ring; we also recently detected a ZEN-catabolizing activity of these metabolites [34]. Based on the mentioned data, GRZ7 was selected for the current research as a source zearalenone-specific lactonohydrolase. The lactonase gene transfer into microbial strains used for feed supplementation with exogenous enzymes seems a promising biotechnology allowing a simultaneous improvement of both the nutritional values of feed ingredients and the safety of these products. Therefore, the present work was aimed at obtaining and studying the target activity of a novel enzyme preparation, amended with recombinant GRZ7 lactonase that was produced by Penicillium canescens possessing the developed system of the biosynthesis of extracellular enzymes. There is an auxotrophic form of the P. canescens strain PCA-10 that can be transformed by plasmid DNA with exogenous genes. We developed PCA-10 as a host strain intended for the production of heterologous enzymes for food, feed, and renewable biomass biorefinery [35] and created a number of novel efficient recombinant strains and enzyme preparations (different cellulases, hemicellulases, pectin lyases, and inulinases) [36-38]. Our studies demonstrated that the rates of the culture growth and biosynthesis of extracellular enzymes in P. canescens are rather high, the fermentation medium is simple in composition and inexpensive, and the fermentation process can be easily scaled. P. canescens secrets only trace amounts of proteases, thus reducing the possibility of a proteolysis of the produced heterologous proteins. All the aforementioned features make the PCA-10 strain economically and 
technologically favorable for the production of extracellular enzymes [35]. The expression system of P. canescens allows the use of three different inducible promoters ( $\mathrm{xn} \mathrm{A}, \mathrm{bgaS}$ and axhA) to develop heterologous and multicopy homologous expression in host $P$. canescens strains [39]. The ability of $P$. canescens to express $P$. verrucolosum cellulases degrading non-starch polysaccharides was demonstrated in [40]. It was shown that the presence of its own xylanase [41] makes the process be the most efficient. Moreover, the P. canescens expression system was used to produce homologous pectinlyase [42] and alpha-galactosidase [43], as well as heterologous Aspergillus sp. inulinases [44].

\section{Results}

\subsection{Cloning and Expression of Zhd101 Gene from C. rosea GRZ7 in Heterologous Hosts}

Cloning of the zhd101 gene from the strain GRZ7 genomic DNA was based on the known polynucleotide sequence of the zearalenone hydrolase gene from C. rosea (GenBank: AB076037.1 [26]). The amplified PCR fragment was $765 \mathrm{bp}$ in length, which corresponds to the size of the zhd101 gene. For the sequence determination, at least four independent clones were analyzed for each amplified product in order to eliminate any PCR errors. The sequencing of the zhd101 gene from the strain GRZ7 in both directions revealed a set of mutations in the codons, which did not lead to a change in the amino acid sequence of ZHD101 and was apparently associated with a different codon usage in the tested GRZ7 and other C. rosea strains [26]. However, two significant differences were found in the triplets GCC $\rightarrow$ GTG and AGC $\rightarrow$ CGC, leading to substitutions in the primary amino acid sequence of S41R and A65V, respectively (Figure 1). No additional substitutions were found in the amino acid sequence ZHD101 from the strain GRZ7.

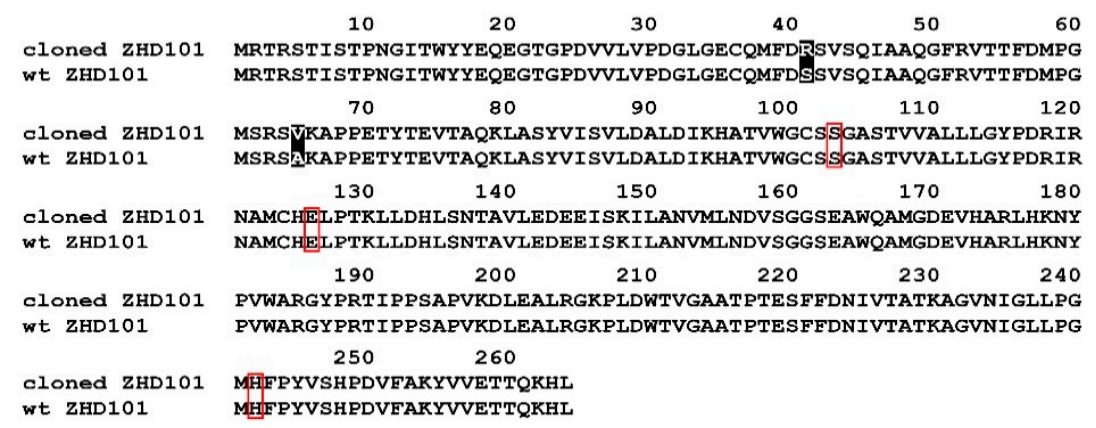

Figure 1. The alignment of the deduced amino acid sequences encoded by the cloned zhd101 from C. rosea GRZ7 and wild-type zhd101. Differences due to the substitution of amino acid residues are shaded. The catalytic triad is indicated with a red box.

The sequence analysis of the zhd101 gene showed that the coding region was not interrupted by introns. Therefore, to obtain primary information on the zhd101 gene expression, the expression system of the E. coli RosettaTM (DE3) pLysS strain was selected under the control of the T7 promoter. SDS-PAGE lysates after a $0.25 \mathrm{mM}$ isopropyl- $\beta$-D-thiogalactoside (IPTG) induction showed the presence of a protein with the mass of $32 \mathrm{kDa}$ (Figure 2).

ZHD101 was identified using the MS peptide fingerprinting technique. The mass spectrum of the ZHD101 is shown in Figure 3A; the matching four tryptic peptides are marked in bold red. The HPLC-analyses of the cell lysates obtained from three randomly selected transformed E. coli clones confirmed the target activity of the recombinant ZHD101. No ZEN-corresponding peak was detected in all lysates tested after an overnight incubation at $25-27^{\circ} \mathrm{C}$ and $\mathrm{pH} 8.3$, while $99.4 \pm 0.21 \%$ of a ZEN standard added before the incubation into a similar lysate of non-transformed E. coli cells was found.

Considering all the advantages of the fungal expression system described above, it was decided to obtain a recombinant strain producing zearalenone hydrolases based on the highly productive $P$. canescens PCA-10 host strain under the control of an inducible xylanase promoter $(x y l F)$. For this, the zhd101 gene from the strain GRZ7 was cloned using the previously developed PC1 [35] and a 
synthetic gene designed with the codon usage of P. canescens PCA-10. Presumably, the use of a synthetic gene would increase the level of heterologous expression [45].

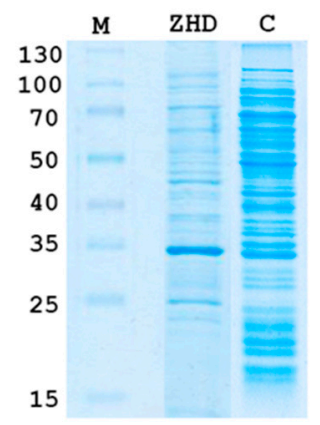

Figure 2. SDS-PAGE of cell lysate after a $0.25 \mathrm{mM}$ isopropyl- $\beta$-D-thiogalactoside induction $(12 \% \mathrm{w} / \mathrm{v}$ gel). ZHD101, a sample of the E. coli RosettaTM (DE3) pLysS strain transformed by the pNIC-ZHD plasmid; C, sample of THE non-transformed E. coli RosettaTM (DE3) pLysS strain; M, molecular mass marker proteins (in $\mathrm{kDa}$, ThermoScientific).

The target protein ZHD101 was successfully expressed and secreted by recombinant $P$. canescens. The SDS-PAGE analyses of the cell-free supernatants of the transformant culture indicated that the molecular weight of the secreted ZHD101 was approximately $30 \mathrm{kDa}$ that corresponds to its mass, theoretically calculated based on its primary sequence (data not shown). The MS analysis also confirmed the presence of the ZHD101 protein in the analyzed supernatants (Figure 3B). As expected, no target protein was found, when the supernatants of the P. canescens host strain PCA-10 were preliminary analyzed by these methods.

In both heterologous systems, lactonohydrolase was found to be expressed more effectively than in the host strain, and P. canescens ZHD101 showed the highest productivity. The average content of the target enzyme in $1 \mathrm{~mL}$ of culture liquid (CL) of the transformed P. canescens was $0.11 \mathrm{mg}$ per $\mathrm{mg}$ of total protein secreted into $\mathrm{CL}$, while $1 \mathrm{~mL}$ of bacterial supernatant contained $0.02 \mathrm{mg}$ of the recombinant ZHD101 per mg of lysed E. coli cells; the productivity of $C$. rosea GRZ7 was almost two orders of magnitude less compared to that of $P$. canescens ZHD101.

The freeze-dried supernatants of a culture liquid of the recombinant $P$. canescens (hereinafter referred to as PR-ZHD) were used as preparations for the enzymatic degradation of ZEN in model solutions and wheat grain artificially infected by a ZEN-producing F. culmorum strain.

\subsection{Enzymatic Degradation of Zearalenone in Model Solutions and Wheat Grain Infected with a} Toxigenic F. culmorum

The degradation dynamics of ZEN in model buffer solutions containing PR-ZHD ( $2 \mathrm{mg} / \mathrm{mL})$ of three randomly selected fungal clones were investigated, using co-incubations of the toxin and the recombinant protein, at different $\mathrm{pH}$ values and temperatures in time course experiments. The tested clones possessed practically equal efficacy towards the ZEN removal from the model solutions, and this process was significantly influenced by both factors studied. 

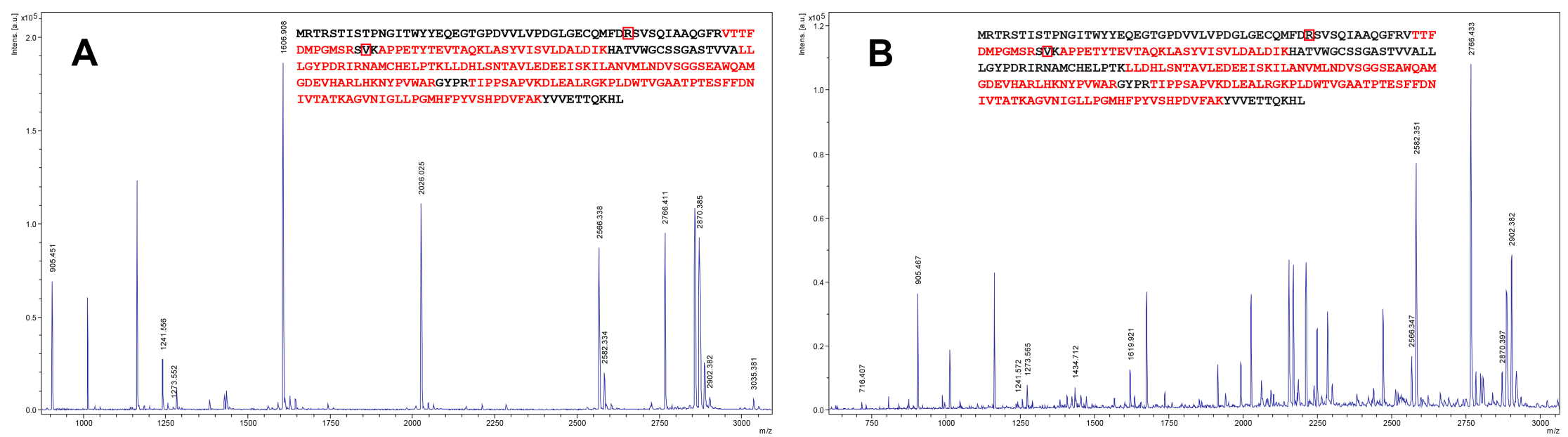

Figure 3. Results of a MALDI-TOF analysis of ZHD101 from the strain GRZ7. The matching four tryptic peptides are marked in bold red, and the substitutions in 41 and 65 positions are squared in red boxes. (A) ZHD101 expressed in the E. coli RosettaTM (DE3) pLysS strain. (B) ZHD101 expressed in the PCA-10 strain. 
In general, PR-ZHD showed the ZEN-degrading activity in the $\mathrm{pH}$ range from 6.5 to 9.5 , but the most rapid ZEN removal from the solutions was observed when it was co-incubated with PR-ZHD at $\mathrm{pH}$ 8.5. In this case, no detectable amount of the toxin was found already after a $3 \mathrm{~h}$ exposure. The co-incubation at other alkaline $\mathrm{pH}$ values (7.5 or 9.5) decreased the ZEN degradation rate (Figure 4) and resulted in a complete removal of the mycotoxin within six or eight hours, respectively (Figure 5A). Under acidic conditions, recombinant ZHD was still able to hydrolyze ZEN at $\mathrm{pH}$ 6.5, while carrying out the reaction at $\mathrm{pH} 5.5$ led to an inactivation of the enzyme (Figure 4). In our experiments, only about $35 \%$ of the toxin added to the PR-ZHD solutions prior incubation was catabolized within three hours at $\mathrm{pH} 6.5$, and a complete $\mathrm{ZEN}$ degradation occurred seven times slower (Figure 5B) than at $\mathrm{pH} 8.5$ (see Figure 4). At pH 5.5, no mycotoxin removal was observed up to the end of $21 \mathrm{~h}$ observations (Figure 5B).

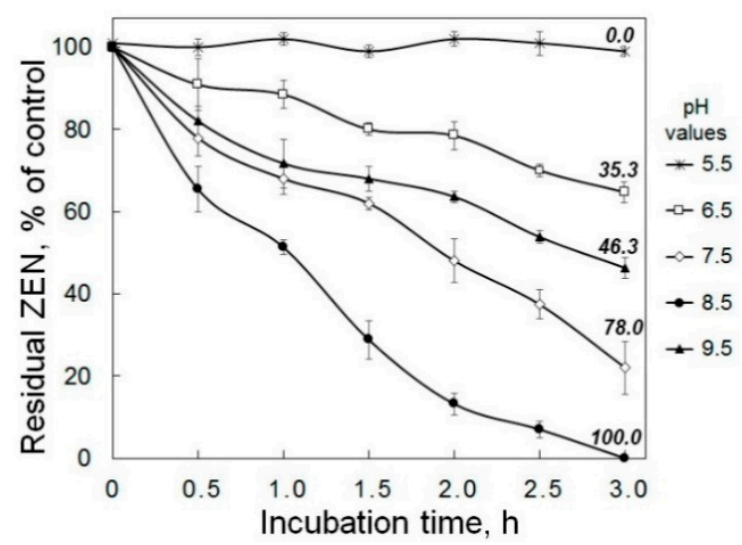

Figure 4. The effect of $\mathrm{pH}$ on the dynamics of zearalenone (ZEN) degradation in model solutions by recombinant lactonohydrolase expressed in Penicillium canescens. The enzyme preparations tested (PR-ZHD) represented the freeze-dried supernatants of culture liquid (CL) of the transformed P. canescens PCA-10, which were dissolved in buffer solutions with various $\mathrm{pH}$ values. The numbers above the curves indicate the percentage of ZEN reduction at the end of the co-incubation with PR-ZHD at $30{ }^{\circ} \mathrm{C}$ compared to the control (ZEN in the corresponding buffer, see Materials and Methods, 6.3). Results expressed as the mean of three experiments $\pm \mathrm{SE}(n=3)$. The representative data are out of one of three transformed PCA-10 clones.
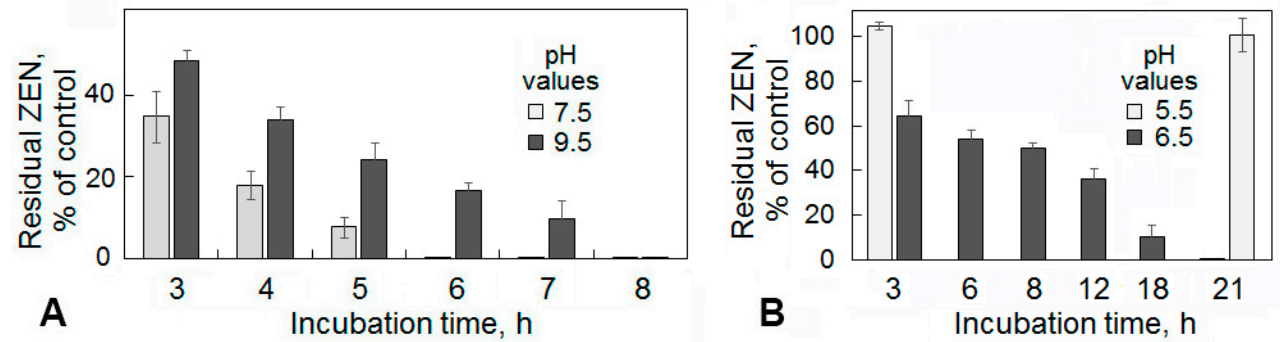

Figure 5. Histograms illustrating the time course of a zearalenone (ZEN) degradation in model solutions by the recombinant lactonohydrolase preparation occurred at non-optimal alkaline (A) and acidic $\mathrm{pH}$ (B) values as well as the irreversible inactivation of the enzyme at $\mathrm{pH} 5.5$ (B). See explanations in Figure 4 .

To characterize the effectiveness of a ZEN degradation in the PR-ZHD-containing solutions at different temperatures, the residual toxin was measured each hour during a $5 \mathrm{~h}$ incubation at the optimum pH 8.0 (Figure 6). The optimum temperature for the degradation was $30^{\circ} \mathrm{C}$. At this temperature, the ZEN concentration was twice reduced within an hour and reached the non-detectable level after $3 \mathrm{~h}$. The enzyme was also active at room temperature and $10{ }^{\circ} \mathrm{C}$, providing an $84 \%$ reduction of the initial ZEN concentration in 3 and $5 \mathrm{~h}$, respectively, as well as a complete degradation at $20^{\circ} \mathrm{C}$ 
within $3 \mathrm{~h}$. A temperature increase resulted in either a rapid reduction of the enzymatic activity $\left(40^{\circ} \mathrm{C}\right)$ or the absolute inactivation of the enzyme $\left(50^{\circ} \mathrm{C}\right)$ (Figure 6$)$. We also found that PR-ZHD remained stable at $4^{\circ} \mathrm{C}$, and its activity was not lost after storage for at least one month (data not shown).

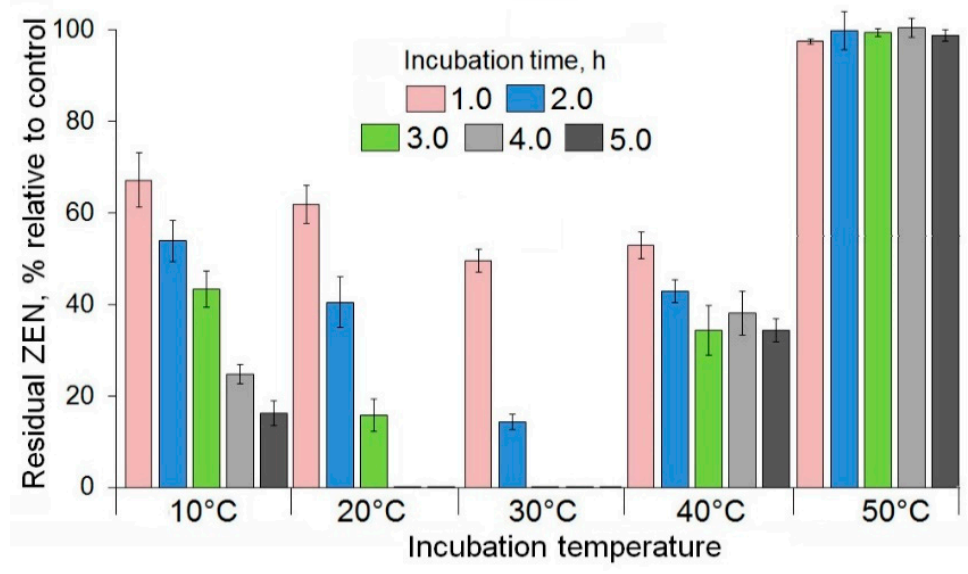

Figure 6. The effect of temperature on the degradation of zearalenone (ZEN) in model solutions after incubation at optimal pH 8.0 with the recombinant lactonohydrolase preparation (PR-ZHD ${ }^{* *}$ ). Results are presented as the means of three experiments, each including three replications. Error bars indicate SD. ** For additional explanations see captions under Figure 4.

A comparison of PR-ZHD and a preparation of ZEN-catabolizing extracellular metabolites obtained from the strain GRZ7 (p-GRZ7) used in our research as a source of a zearalenone-specific lactonohydrolase gene showed that the target activity of PR-ZHD was significantly more effective (Figure 7). After a 3 day incubation under optimal conditions, the average reduction of ZEN content exposed to p-GRZ7 used at a concentration four-fold higher than that of PR-ZHD reached 66\% (Figure 7A,C).
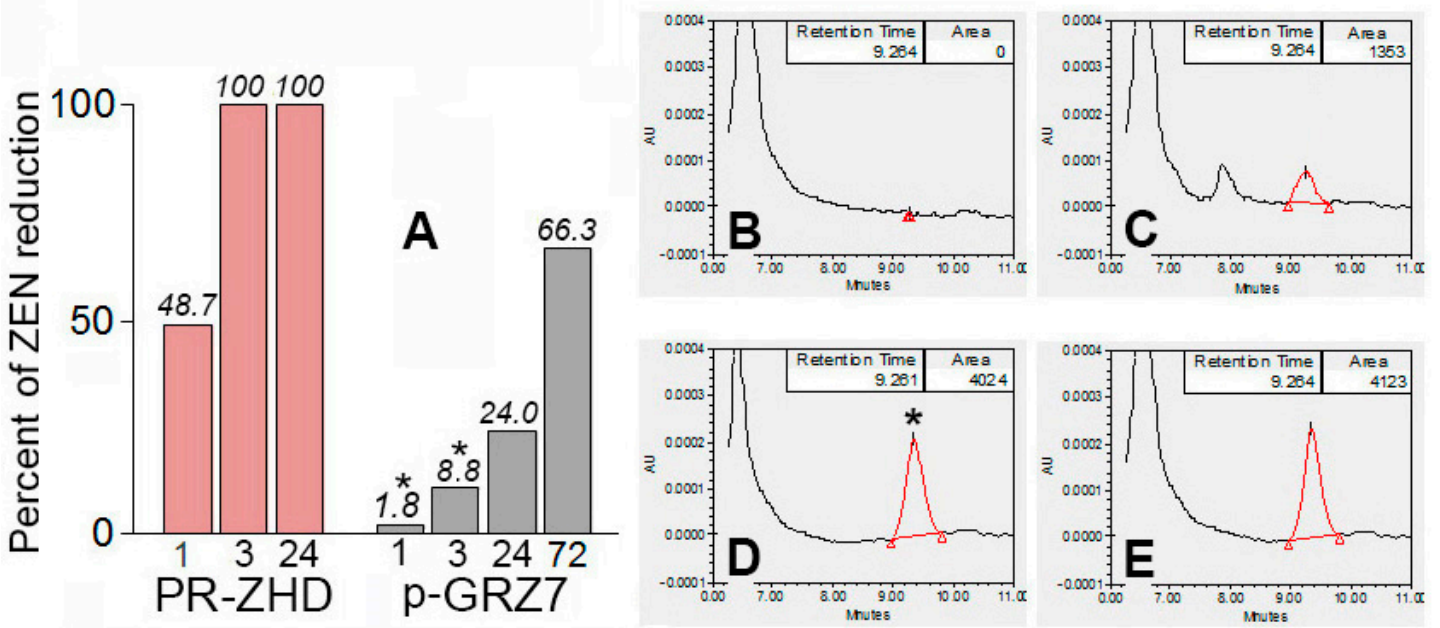

Figure 7. Histogram showing different effectiveness of zearalenone (ZEN) degradation in the preparations of the recombinant lactonohydrolase (PR-ZHD) and ZEN-catabolizing extracellular metabolites obtained from the C. rosea strain GRZ7 (p-GRZ7), which was used a source of zhd101 (A); and the corresponding chromatograms illustrating the results of the overnight ZEN incubation in PR-ZHD (B), p-GRZ7 (C) or a preparation from the non-transformed host P. canescens PCA-10 (D) obtained similar to PR-ZHD. (E) The commercial ZEN standard (Sigma-Aldrich, USA) in $100 \mathrm{mM}$ Tris- $\mathrm{HCl}$ buffer after incubation under the same conditions (control to D). ZEN was added into the preparations up to the equal concentration $(5 \mu \mathrm{g} / \mathrm{mL})$, while the p-GRZ7 concentration four-fold exceeded that of PR-ZHD. A co-incubation was carried out at $\mathrm{pH} 8.0$ and $30^{\circ} \mathrm{C}$. Asterisks indicate the lack of statistically significant differences between the corresponding controls and treatments at $p \leq 0.05$. 
To examine if PR-ZHD can serve as a potential tool for the decontamination of a fungal-damaged ZEN-contaminated grain, a pathogenic F. culmorum strain able to produce this toxin was grown on autoclaved wheat kernels. The extracts of artificially infected grain were found to contain ZEN. In contrast, these extracts were ZEN-free if the samples of the flour prepared from contaminated grain were co-incubated overnight with PR-ZHD at $\mathrm{pH} 8.0$ and $30^{\circ} \mathrm{C}$ (Table 1). No reduction of the toxin content was observed in the extracts from infected kernels, if the flour suspension was exposed to a freeze-dried supernatant from the non-transformed host PCA-10 (pPCA10) under the same conditions. In addition, co-incubation with pPCA10 did not result in any removal of the ZEN standard added to the flour suspension prior to the treatment with this preparation (Table 1).

Table 1. Zearalenone (ZEN) content in the extracts of autoclaved wheat grain artificially infected with ZEN-producing F. culmorum.

\begin{tabular}{cc}
\hline Treatments & $\begin{array}{c}\text { ZEN, } \boldsymbol{\mu g} / \mathbf{g} \\
(\mathbf{M} \pm \mathbf{S E})\end{array}$ \\
\hline Infected grain (control) & $15.58 \pm 3,07$ \\
Infected grain + PR-ZHD & $<0.2^{* *}$ \\
Infected grain + pPCA10 & $15.73 \pm 4.35$ \\
Non-infected grain + ZEN *** & $3.15 \pm 0.09 * * *$ \\
Non-infected grain + ZEN + pPCA10 & $3.17 \pm 0.13$ \\
\hline
\end{tabular}

* PR-ZHD was added to a final concentration of $8 \mathrm{mg} / \mathrm{g}$ of dried grain. ${ }^{* *}$ The limit of ZEN detection in the grain extracts was $0.2 \mu \mathrm{g} / \mathrm{g}$. ${ }^{* * *}$ Prior to treatment with pPCA10, the samples were supplemented with an aliquot of a ZEN standard (Sigma-Aldrich, St. Louis, MO, USA) to a final concentration of $4 \mu \mathrm{g} / \mathrm{g}$. The average ZEN recovery was $79 \%$.

\section{Discussion}

As with other mycotoxins, numerous physical and chemical methods intended to remove a ZEN fusariotoxin from agricultural products are being developed today. However, only a few of these methods are safe and may be implemented in practice [46]. Biological decontamination based on the use of mycotoxin-degrading microorganisms as feed additives has less limitations, but can be associated with some disadvantages, such as the production of undesirable metabolites and the worsening of the quality of products. However, mycotoxin destroying or biotransformation by extracellular enzyme preparations of microbial origin allows avoiding the drawbacks of a decontamination by living microorganisms. An additional advantage of such preparations is that they can be manufactured by large-scale fermentation and can include not only toxin-degrading enzymes but also other ones possessing alternative useful properties. In this regard, this study focused on the introduction of the ZEN-degrading activity into $P$. canescens PCA-10 producing a complex of endogenous hemicellulases such as xylanases, arabinofuranosidases, $\beta$-galactosidase, etc.

We were able to receive several transformed clones expressing and secreting a novel recombinant ZHD101 protein that rapidly removed ZEN from the model solutions and was able to decontaminate the wheat grain infected with a toxin-producing fungus.

According to our experimental data, the ZHD101 amino acid sequence of strain GRZ7 (265 aa) is slightly different from the closest homologue of ZHD101 from C. rosea. The amino acid sequence of ZHD101 from GRZ7 showed a high identity (99\%) with ZHD101 from C. rosea with the putative catalytic triplet SHE motif (Ser102-His242-Glu126) [47]. It should be noted that the Ala65Val substitution found in the new ZHD101 is located in an unstructured region of the protein globule, and the presence of valine at the position 65 can lead to the stabilization of the protein globule due to the hydrophobization of the chain. As for the Ser41Arg substitution, it is located in the $\alpha$-helix, which can lead to some destabilization; however, this residue is far from the Ser102-His242-Glu126 triad, which determines the catalytic activity of ZHD101 [47] (Figure 1).

In general, our results on determining the $\mathrm{pH}$ and temperature dependence of the ZEN-degrading activity of the enzyme secreted by the transformed P. canescens PCA-10 coincided with the data reported 
for the ZHD of C. rosea IFO 7063 [26] as well as for the recombinant ZHD101 and ZLHY6, which were expressed in Escherichia coli and Pichia pastoris, respectively [28,48]. However, ZHD101 expressed in PCA-10 clones had the highest activity at $\mathrm{pH} 8.5$ (similar to ZLHY6) and was much less active under more alkaline conditions, differing from the enzyme of $C$. rosea, which had the maximum activity at $\mathrm{pH} 9-10$ [26]. Moreover, the ZEN removal at $\mathrm{pH} 7.5$ occurred more rapidly than at $\mathrm{pH} 9.5$. Like the aforementioned preparations of lactonohydrolases, PR-ZHD was inactivated at $50{ }^{\circ} \mathrm{C}$ and an acidic $\mathrm{pH}$ below 6.0. It is important to note that even at $10^{\circ} \mathrm{C}$ PR-ZHD was able to degrade $80-86 \%$ of the toxin within $5 \mathrm{~h}$ of incubation (Figure 6), since this discovery can be significant for a post-harvest decontamination of stored feeds.

The host strain GRZ7 produced much less lactonohydrolase compared to the transformed P. canescens PCA-10 clones. Our preliminary experiments [34] revealed the necessity of at least a ten-fold concentration of GRZ7 extracellular metabolites in order to provide a significant level of ZEN degradation. This suggested the productivity of GRZ7 turned out to be insufficient to consider it as a prospective producer of a ZEN-degrading enzyme. At the same time, we showed that $P$. canescens PCA-10 possessed the well developed system for the biosynthesis of extracellular enzymes, as well as some other advantages as a super-producer of various enzyme preparations [36-44]. By transforming this active producer of extracellular metabolites, we succeeded in obtaining recombinant $P$. canescens, of which the enzyme preparation showed ZEN-degrading efficacy, significantly exceeding that of the host $C$. rosea strain.

As known, considerable amounts of nutrients and fluids (e.g., xylans and other polysaccharides) are excreted from the animal organisms without being metabolized [49]. It is worth noting that our recent experiments suggest that the freeze-dried supernatants of the transformed PCA-10 retained the ability to destroy polysaccharides. However, further investigations are necessary to confirm the PR-ZHD promise for the application on ZEN-polluted forage wheat with the purpose of simultaneous decontamination and improving the availability of feed nutritional components. Another possible way to provide a highly effective biological protection of agricultural feedstock from contamination is a combination of mycotoxin-degrading enzyme preparations and the natural inhibitors of the toxigenesis [50]. Such preparations might be used for providing an additional feed decontamination in those cases when an inhibitor incompletely suppresses the biosynthesis of mycotoxins. Our studies of PR-ZHD, including the dose-rate effect and testing the enzyme preparation on cereal samples naturally contaminated with ZEN, as well as the assessment of the possibility to combine PR-ZHD with some inhibitors of ZEN and other polyketide mycotoxin biosynthesis, are in progress.

It should be also noted that the use of the heterologous production system allowed us to simplify obtaining the enzyme, since no additional purification or culture concentration were needed. In addition, the use of enzymatic preparations for mycotoxin degradation is more preferable than the use of toxin-degrading microorganisms, since microorganisms may also produce some undesirable components or consume the substrate impairing its nutritional value. Thus, the results of the current research open avenues for a potential application of recombinant lactonohydrolase in feed production. If large-scale tests on different feed substrates will show good results, and toxicological studies will confirm the safety of the preparation, it can be industrially produced to develop additives increasing the safety of grain and other feeds.

\section{Materials and Methods}

\subsection{Microbial Strains and Cultivation Media}

The Escherichia coli MachI ${ }^{\mathrm{TM}}$ T1R strain (Thermo Fisher Scientific Inc., Waltman, MA, USA) was used to obtain competent cells in the subcloning experiments. The Escherichia coli Rosetta ${ }^{\mathrm{TM}}$ (DE3) pLysS strain (Thermo Fisher Scientific Inc., Waltman, MA, USA) was used to obtain competent cells for zhd101 gene expression. The Penicillium canescens PCA-10 strain [35] was used as an auxotrophic host strain $(\triangle n i a D)$ in fungal transformation. The $C$. rosea strain GRZ7 producing ZEN-destroying enzymes 
and earlier isolated from the fungal consortium of toxigenic Aspergillus flavus [51], was applied for the isolation of genomic DNA.

Total genomic DNA was isolated from the $C$. rosea GRZ7 mycelium after a 5 day incubation on minimal medium $(\mathrm{g} / \mathrm{L}): \mathrm{MgSO}_{4} \cdot 7 \mathrm{H}_{2} \mathrm{O}-0.2, \mathrm{NH}_{4} \mathrm{NO}_{3}-1.0, \mathrm{~K}_{2} \mathrm{HPO}_{4}-0.9, \mathrm{KCl}-0.15, \mathrm{FeCl}_{2}-0.002$, $\mathrm{ZnSO}_{4}-0.002$, glucose-5.

The screening of transformants was carried out in shake flasks (total volume $500 \mathrm{~mL}$, fermentation broth volume $100 \mathrm{~mL}$ ). E. coli recombinant strains were cultivated using standard Luria-Bertani broth supplemented with $50 \mu \mathrm{g} / \mathrm{mL}$ kanamycin, $34 \mu \mathrm{g} / \mathrm{mL}$ chloramphenicol and $0.25 \mathrm{mM}$ isopropyl $\beta$-D-thiogalactoside for expression induction.

P. canescens cultivation media contained $(\mathrm{g} / \mathrm{L})$ : soybean hulls-45, corn extract $-50, \mathrm{KH}_{2} \mathrm{PO}_{4}-15$.

\subsection{Expression of Zhd101 Gene in Heterologous Hosts and ZHD101 Identification}

The coding region of the zhd101 gene (GenBank AN: AB076037.1) was amplified by PCR with the ZHD-LIC5 and ZHD-LIC3 primer pair (Table 2) and the GRZ7 genomic DNA isolated using a QIAquick Plant Mini Kit (QIAGEN, Valencia, CA, USA) as a template. The obtained PCR product (765 bp) was cloned into pNIC-Bsa4 vector (a gift from Opher Gileadi, Addgene plasmid \#26103 [52]) using the ligation independent cloning protocol [53]. The resulting pNIC-ZHD plasmid (Figure S1A, see Supplementary Materials) was isolated using a QIAquick Miniprep Kit (QIAGEN, Valencia, CA, USA). The desirable zhd101 insertion in a pNIC-Bsa4 vector was confirmed by the DNA sequencing of a full-size pNIC-ZHD plasmid. Then pNIC-ZHD was used to produce the recombinant ZHD101 in E. coli Rosetta $^{\mathrm{TM}}$ (DE3) pLysS competent cells.

The screening of E. coli transformants was carried out in the Luria-Bertani (LB) broth $12 \mathrm{~h}$ after induction with $0.25 \mathrm{mM}$ IPTG. The ZHD101 expression was characterized by SDS-PAGE in $12 \%$ gel using a Mini Protean II equipment (Bio-Rad Laboratories, USA) and a PageRuler Unstained Broad Range Protein ladder (ThermoFisher Scientific, Waltham, MA, USA). For the enzyme identification, pieces of protein bands were cut off the electrophoretic gel, digested with trypsin according to a standard protocol [54], and the resulting peptide mixture was analyzed by MALDI-TOF mass spectrometry (MS) using an UltrafleXtreme mass spectrometer (Bruker Daltonik GmbH, Bremen, Germany). The MS data were analyzed using the online MASCOT service (http://www.matrixscience.com/).

A codon analysis of the zhd101 gene from GRZ7 was carried out using a Sequence Manipulation Suite (www.bioinformatics.org/sms2/codon_usage.html). A synthetic zhd101 gene was designed using a GenScript program (www.genscript.com/gensmart-free-gene-codon-optimization.html) based on the Aspergillus niger codon usage.

Table 2. Primers and oligonucleotides used in the study.

\begin{tabular}{cr}
\hline Primer Name & Sequence \\
\hline ZHD-LIC5 & $5^{\prime}$ - TACTTCCAATCCATGCGCACTCGCAGCACAATCTCGAC -3' \\
ZHD-LIC3 & $5^{\prime}$ - TATCCACCTTTACTGTCAAAGATGCTTCTGCGTAGTTTC -3' \\
ZHD-UpLIC & $5^{\prime}$-CAAACAGAAGCAACCGACACAATGCGCACTCGCAGCACAATCTCGA -3' \\
ZHD-LowLIC & $5^{\prime}$ - AGAGCAAGCCGAGCAGGTTCAAAGATGCTTCTGCGTAG -3' \\
\hline
\end{tabular}

The cloning of the synthetic zhd101 gene (Evrogen, Moscow, Russia) into the P. canescens PCA-10 $(\triangle n i a D)$ auxotrophic strain was carried out as described previously $[55,56]$. The pair of oligonucleotides, ZHD-UpLIC and ZHD-LowLIC, was constructed to amplify the zhd101s gene. Briefly, the zhd101s gene was cloned into a modified linear PC1 shuttle vector containing a promoter and the terminator regions of the $x y l A$ gene-encoding xylanase A from P. canescens [35]. Then, the resulting expression plasmid pXEG-ZHD (Figure S1B) was transformed into competent E. coli MachI cells, and the produced DNA material was supplied for analysis. The E. coli MachI cells were cultured as described elsewhere [56]. The absence of additional mutations, deletions, or insertions in the zhd101s gene was confirmed by its sequencing in both directions according to Sanger et al. [57]. 
The pXEG-ZHD plasmid was directed into the protoplasts of the host P. canescens PCA-10 ( $\triangle$ niaD) strain together with a pSTA10 plasmid $(10: 1, \mu \mathrm{g})$ using the modified method described by Aleksenko et al. [58]. The efficiency of integration amounted to $15-20$ clones per $1 \mu \mathrm{g}$ of the target DNA that corresponded to a standard frequency of the transformation for the fungal genus Penicillium [58]. Stable transformants were grown in shake flasks for 6 days using a small volume $(100 \mathrm{~mL})$ of the liquid cultivation medium as described above.

The screening of recombinant $P$. canescens ZHD strains was carried out directly from colonies with the use of a routine PCR protocol and Phire Hot Start II DNA Polymerase (ThermoFisher Scientific, Waltham, MA, USA) (Figure S2).

The selected clones were cultivated in a 3 L glass KF-104/3 fermenter (Prointex, Russia). The medium composition for $P$. canescens fermentation was identical to that in shake flasks (see above). Fermentation was carried out for $144 \mathrm{~h}$. Finally, the culture broth was centrifuged at $4000 \mathrm{rpm}$ for $20 \mathrm{~min}$ on an Avanti JXN-26 centrifuge (Beckman Coulter, Brea, CA, USA) to remove the biomass and insoluble components of the nutrient medium. The supernatant was freeze-dried on a VirTis BenchTop 2K ES freeze dryer (SP Scientific, Warminster, PA, USA). The resulting lyophilizate was referred to as the ZHD recombinant preparation (PR-ZHD). Additionally, a freeze-dried supernatant of the culture liquid prepared under similar fermentation conditions was obtained from a non-transformed recipient PCA-10 strain.

\subsection{Estimation of the Zearalenone Removal from Model Solutions under Different Conditions}

PR-ZHD samples were dissolved in $100 \mathrm{mM}$ Tris- $\mathrm{HCl}$ buffer with a $\mathrm{pH}$ ranging from 6.5 to 9.5, or $100 \mathrm{mM}$ acetate buffer with $\mathrm{pH} 5.5$ to a final concentration of $2 \mathrm{mg} / \mathrm{mL}$, and sterilized by passing through a $0.22 \mu \mathrm{m}$ Millipore filter. The sterilized PR-ZHD solutions were supplemented with a commercial ZEN (Sigma-Aldrich, St. Louis, MO, USA) dissolved in a minimum volume of methanol up to a final concentration of $5.0 \mu \mathrm{g} / \mathrm{mL}$ and incubated at $30^{\circ} \mathrm{C}$ for different time intervals until a complete ZEN removal from the incubation solution. Following that, the effect of different temperatures $\left(10-50^{\circ} \mathrm{C}\right.$ for $\left.5 \mathrm{~h}\right)$ on the degradation process at the optimal $\mathrm{pH}$ was investigated. The reaction was terminated by $1 \mathrm{~N} \mathrm{HCl}$. The corresponding preparation obtained from non-transformed PCA-10 (pPCA10) was used as the control. A freeze-dried sample of a ZEN-degrading fraction of GRZ7 extracellular metabolites (p-GRZ7) with a final concentration of $8 \mathrm{mg} / \mathrm{mL}$, which was prepared by ultrafiltration, precipitation with ammonium sulfate, and partial purification by the anion-exchange chromatography $[26,33]$, was used to compare the ZEN degradation by the recombinant ZHD and the metabolites of the initial C. rosea strain.

To confirm the ZEN-degrading activity of ZHD produced in the E. coli expression system, the fresh lysates of the transformed E. coli clones were examined after an overnight incubation at $27-28{ }^{\circ} \mathrm{C}$ and $\mathrm{pH} 8.3$ [59].

\subsection{Decontamination Test}

To contaminate the wheat grain with ZEN, $2.0 \mathrm{~mL}$ of a macroconidial suspension ( $10^{6}$ conidia/mL) of the toxin-producing F. culmorum strain grown on Chapek agar was added into $250 \mathrm{~mL}$ flasks (in three replications) each containing $50 \mathrm{~g}$ of moistened autoclaved wheat grain. The flasks were incubated at $25-26{ }^{\circ} \mathrm{C}$ for 14 days. The infected grain was dried at $40{ }^{\circ} \mathrm{C}$ to a constant weight and powdered in a laboratory mill. Randomized flour samples $(5 \mathrm{~g})$ from each flask were placed into $250 \mathrm{~mL}$ flasks, suspended in $60 \mathrm{~mL}$ of a $100 \mathrm{mM}$ Tris-HCL buffer $(\mathrm{pH}$ 8.5) and supplemented with PR-ZHD at a rate of $8 \mathrm{mg}$ per gram of dried grain. After an overnight incubation at $30^{\circ} \mathrm{C}$ at a slight automated agitation, acetonitrile was added to a final concentration of $84 \%$, and the suspensions were extracted at vigorous shaking for $30 \mathrm{~min}$. ZEN was further purified from the extract as described earlier [60]. The precipitate obtained after the evaporation of the purified ZEN-containing extract on a rotary evaporator was dissolved in a minimum volume of a methanol-acetonitrile mixture (1:1) and analyzed by reversed-phase HPLC. 


\subsection{Quantification ZEN Residues}

The residual ZEN content in the model solutions or the extracts from ZEN-contaminated wheat was analyzed using a Waters1525 Breeze HPLC system equipped with a Waters 2487 UV detector (Waters Corp, USA). Aliquots of the tested solutions $(10 \mu \mathrm{L})$ were applied on a Symmetry C18 $(5 \mu \mathrm{m}$, $150 \times 4.6 \mathrm{~mm}$ ) temperature-controlled $\left(27^{\circ} \mathrm{C}\right)$ column (Waters Corp., Milford, MA, USA), eluted with a acetonitrile-methanol-water mix (1:1:0.75) at a rate of $0.8 \mathrm{~mL} / \mathrm{min}$, and detected at $254 \mathrm{~nm}$. To determine the percent of recovery, the ZEN standard (Sigma-Aldrich, St. Louis, MO, USA) was added into a sample of non-infected wheat grain ( $4 \mu \mathrm{g}$ per $1 \mathrm{~g}$ of the milled grain) prior to the extraction. The limit of detection in the wheat grain extracts was $0.2 \mathrm{mg} / \mathrm{kg}$, while the recovery amounted to $79 \%$. The linear dependence of the peak area on the analyte amount was observed at a sensitivity of 0.01 units of the absorption/scale.

\subsection{Statistical Analysis}

Tests on the ZEN degradation in the model solutions or infected grain samples included three replications per treatment. Quantitative results were analyzed by a STATISTICA v. 6.1 software (StatSoft Inc., Tulsa, OK, USA) and presented as the mean values of the measurements obtained in at least three independent experimental series. The significance of differences $(p<0.05)$ of the means between treatments and controls were determined using a $t$-test for the independent variables.

Supplementary Materials: The following are available online at http://www.mdpi.com/2072-6651/12/8/475/s1, Figure S1: The schematic diagram of the two plasmids for expression into: E. coli RosettaTM (DE3) pLysS strain and Penicillium canescens PCA-10, Figure S2: Screening of the recombinant P. canescens ZHD strains (1-18).

Author Contributions: A.R., L.S. conceived, designed and analyzed the experiments and wrote the paper. I.Z., D.O., O.M., N.S., V.D., O.S., performed the experiments and analyzed the data. L.S., V.D., and A.S. developed the paper conception, discussed the results and edited the manuscript. All authors have read and agreed to the published version of the manuscript.

Funding: This work was funded by the Russian Science Foundation (project No. 19-76-10031) except of experiments on heterologous expression of zhd101 gene that were started and carried out earlier in the course of the previous RSF project No. 14-16-00150.

Acknowledgments: We thank the Federal Research Centre "Fundamentals of Biotechnology" of the Russian Academy of Sciences for the possibility to fulfil a part of measurements using the equipment of the Shared-Access Equipment Centre "Industrial Biotechnology".

Conflicts of Interest: The authors declare no conflict of interest.

\section{References}

1. Manubolu, M.; Goodla, L.; Pathakoti, K.; Malmlöf, K. Enzymes as direct decontaminating agents-mycotoxins. In Enzymes in Human and Animal Nutrition: Principles and Perspectives; Nunes, C.S., Kumar, V., Eds.; Academic Press: Cambridge, MA, USA, 2018; pp. 313-330. ISBN 978-0-12-805419-2. [CrossRef]

2. Dai, Z.; Cui, L.; Li, J.; Wang, B.; Guo, L.; Wu, Z.; Zhu, W.; Wu, G. Fermentation techniques in feed production. In Animal Agriculture; Bazer, F.W., Lamb, G.C., Wu, G., Eds.; Academic Press: Cambridge, MA, USA, 2020; pp. 407-429. ISBN 978-0-12-817052-6. [CrossRef]

3. Zain, M.E. Impact of mycotoxins on humans and animals. J. Saudi Chem. Soc. 2011, 15, 129-144. [CrossRef]

4. Zinedine, A.; Soriano, J.M.; Moltó, J.C.; Mañes, J. Review on the toxicity, occurrence, metabolism, detoxification, regulations and intake of zearalenone. Food Chem. Toxicol. 2007, 45, 1-18. [CrossRef] [PubMed]

5. Maragos, C.M. Zearalenone occurrence and human exposure. World Mycotoxin J. 2010, 3, 369-383. [CrossRef]

6. Mally, A.; Solfrizzo, M.; Degen, G.H. Biomonitoring of the mycotoxin zearalenone: Current state-of-the art and application to human exposure assessment. Arch. Toxicol. 2016, 90, 1281-1292. [CrossRef]

7. Burkin, A.A.; Kononenko, G.P.; Gavrilova, O.P.; Gagkaeva, T.Y. About zearalenone levels in grass fodders and toxin producing activity of Fusarium fungi. Agricul. Biol. 2015, 50, 255-262. [CrossRef]

8. Gruber-Dorninger, C.; Jenkins, T.; Schatzmayr, G. Global mycotoxin occurrence in feed: A ten-year survey. Toxins 2019, 11, 375. [CrossRef] 
9. Richard, J.L. Some major mycotoxins and their mycotoxicoses-An overview. Int. J. Food Microbiol. 2007, 119, 3-10. [CrossRef]

10. Gajęcki, M.; Gajęcka, M.; Jakimiuk, E.; Zielonka, Ł.; Obremski, K. Zearalenone: Undesirable substance. In Mycotoxins in Food, Feed and Bioweapons; Rai, M., Varma, A., Eds.; Springer: Berlin/Heidelberg, Germany, 2009; pp. 131-144. ISBN 978-3-642-00724-8. [CrossRef]

11. Kowalska, K.; Habrowska-Górczyńska, D.E.; Piastowska-Ciesielska, A.W. Zearalenone as an endocrine disruptor in humans. Environ. Toxicol. Pharmacol. 2016, 48, 141-149. [CrossRef]

12. Mao, J.; He, B.; Zhang, L.; Li, P.; Zhang, Q.; Ding, X.; Zhang, W. A Structure identification and toxicity assessment of the degradation products of aflatoxin B1 in peanut oil under UV irradiation. Toxins 2016, 8, 332. [CrossRef]

13. Li, P.; Su, R.; Yin, R.; Lai, D.; Wang, M.; Liu, Y. Detoxification of mycotoxins through biotransformation. Toxins 2020, 12, 121. [CrossRef]

14. Abassi, H.; Ayed-Boussema, I.; Shirley, S.; Abid, S.; Bacha, H.; Micheau, O. The mycotoxin zearalenone enhances cell proliferation, colony formation and promotes cell migration in the human colon carcinoma cell line HCT116. Toxicol. Lett. 2016, 254, 1-7. [CrossRef] [PubMed]

15. Hueza, I.M.; Raspantini, P.C.; Raspantini, L.E.; Latorre, A.O.; Górniak, S.L. Zearalenone, an estrogenic mycotoxin, is an immunotoxic compound. Toxins 2014, 6, 1080-1095. [CrossRef] [PubMed]

16. Kamimura, H. Conversion of zearalenone to zearalenone glycoside by Rhizopus sp. Appl. Environ. Microbiol. 1986, 52, 515-519. [CrossRef]

17. Chen, S.-W.; Wang, H.-T.; Shih, W.-Y.; Ciou, Y.-A.; Chang, Y.-Y.; Ananda, L.; Wang, S.-Y.; Hsu, J.-T. Application of zearalenone (ZEN)-detoxifying Bacillus in animal feed decontamination through fermentation. Toxins 2019, 11, 330. [CrossRef] [PubMed]

18. Kakeya, H.; Takahashi-Ando, N.; Kimura, M.; Onose, R.; Yamaguchi, I.; Osada, H. Biotransformation of the mycotoxin, zearalenone, to a non-estrogenic compound by a fungal strain of Clonostachys sp. Biosci. Biotechnol. Biochem. 2002, 66, 2723-2726. [CrossRef] [PubMed]

19. Kriszt, R.; Krifaton, C.; Szoboszlay, S.; Cserháti, M.; Kriszt, B.; Kukolya, J.; Czéh, A.; Fehér-Tóth, S.; Török, L.; Szőke, Z.; et al. A new zearalenone biodegradation strategy using non-pathogenic Rhodococcus pyridinivorans K408 strain. PLoS ONE 2012, 7, e43608. [CrossRef]

20. Wang, J.Q.; Yang, F.; Yang, P.L.; Liu, J.; Lv, Z.H. Microbial reduction of zearalenone by a new isolated Lysinibacillus sp. ZJ-2016-1. World Mycotoxin J. 2018, 11, 1-8. [CrossRef]

21. Banu, I.; Lupu, A.; Aprodu, I. Degradation of zearalenone by laccase enzyme. Sci. Study Res. 2013, 14, 79-84.

22. Paris, M.P.K.; Schweiger, W.; Hametner, C.; Stuckler, R.; Muehlbauer, G.J.; Varga, E.; Krska, R.; Berthiller, F.; Adam, G. Zearalenone-16-O-glucoside: A new masked mycotoxin. J. Agric. Food Chem. 2014, 62, 1181-1189. [CrossRef]

23. Zheng, Y.; Liu, W.; Chen, C.-C.; Hu, X.; Guo, R.-T. Crystal structure of a mycoestrogen-detoxifying lactonase from Rhinocladiella mackenziei: Molecular insight into ZHD substrate selectivity. ACS Catal. 2018, 8, 4294-4298. [CrossRef]

24. de Oliveira Garcia, S.; Vanessa Marimón Sibaja, K.; Vilar Nogueira, W.; Carla Penteado Feltrin, A.; Fabiano Alvares Pinheiro, D.; Barnes Rodrigues Cerqueira, M.; Badiale Furlong, E.; Garda-Buffon, J. Peroxidase as a simultaneous degradation agent of ochratoxin A and zearalenone applied to model solution and beer. Food Res. Int. 2020, 131, 109039. [CrossRef] [PubMed]

25. Peng, W.; Ko, T.-P.; Yang, Y.; Zheng, Y.; Chen, C.-C.; Zhu, Z.; Huang, C.; Zeng, Y.-F.; Huang, J.-W.; Wang, A.; et al. Crystal structure and substrate-binding mode of the mycoestrogen-detoxifying lactonase ZHD from Clonostachys rosea. RSC Adv. 2014, 107, 62321-62325. [CrossRef]

26. Takahashi-Ando, N.; Kimura, M.; Kakeya, H.; Osada, H.; Yamaguchi, I. A novel lactonohydrolase responsible for the detoxification of zearalenone: Enzyme purification and gene cloning. Biochem. J. 2002, 365, 1-6. [CrossRef] [PubMed]

27. Chang, X.; Liu, H.; Sun, J.; Wang, J.; Zhao, C.; Zhang, W.; Zhang, J.; Sun, C. Zearalenone removal from corn oil by an enzymatic strategy. Toxins 2020, 12, 117. [CrossRef]

28. Takahashi-Ando, N.; Ohsato, S.; Shibata, T.; Hamamoto, H.; Yamaguchi, I.; Kimura, M. Metabolism of zearalenone by genetically modified organisms expressing the detoxification gene from Clonostachys rosea. Appl. Environ. Microbiol. 2004, 70, 3239-3245. [CrossRef] [PubMed] 
29. Vekiru, E.; Fruhauf, S.; Hametner, C.; Schatzmayr, G.; Krska, R.; Moll, W.D.; Schuhmacher, R. Isolation and characterization of enzymatic zearalenone hydrolysis reaction products. World Mycotoxin J. 2016, 9, 353-363. [CrossRef]

30. Zhou, J.; Zhu, L.; Chen, J.; Wang, W.; Zhang, R.; Li, Y.; Zhang, Q.; Wang, W. Degradation mechanism for zearalenone ring-cleavage by zearalenone hydrolase RmZHD: A QM/MM study. Sci. Total Environ. 2019, 709, 135897. [CrossRef]

31. Higa-Nishiyama, A.; Takahashi-Ando, N.; Shimizu, T.; Kudo, T.; Yamaguchi, I.; Kimura, M. A model transgenic cereal plant with detoxification activity for the estrogenic mycotoxin zearalenone. Transgenic Res. 2005, 14, 713-717. [CrossRef]

32. Takahashi-Ando, N.; Tokai, T.; Hamamoto, H.; Yamaguchi, I.; Kimura, M. Efficient decontamination of zearalenone, the mycotoxin of cereal pathogen, by transgenic yeasts through the expression of a synthetic lactonohydrolase gene. Appl. Microbiol. Biotechnol. 2005, 67, 838-844. [CrossRef]

33. Shcherbakova, L.A.; Mikityuk, O.D.; Nazarova, T.A.; Dzhavakhiya, V.G. Study of aflatoxin B1-destroying activity of Gliocladium roseum and Trichoderma viride and their antagonism toward toxigenic Aspergillus flavus. Agric. Biol. 2016, 51, 946-950. [CrossRef]

34. Mikityuk, O.D.; Statsyuk, N.V.; Nazarova, T.A.; Shcherbakova, L.A.; Dzhavakhiya, V.G. Mycotoxin degradation by microbial metabolites. In Proceedings of the Abstracts of International Scientific Conference PLAMIC2020 “Plants and Microorganisms: Biotechnology of the Future”, Saratov, Russia, 5-9 October 2020; in press.

35. Sinitsyn, A.P.; Rozhkova, A.M. Penicillium canescens host as the platform for development of a new recombinant strains producers of carbohydrases. In Microorganisms in Biorefineries; Kamm, B., Ed.; Springer: Berlin/Heidelberg, Germany, 2015; pp. 1-19. [CrossRef]

36. Benevolenskaya, E.A.; Benevolensky, M.S.; Zatsepin, S.S.; Zorov, I.N.; Rozhkova, A.M.; Sinitsyn, A.P.; Sereda, A.S.; Bushina, E.V. A novel recombinant strain of filamentous fungus Penicillium canescens PEP3 and obtaining on its base a complex enzyme preparation with endo- and exoproteolytic activities. Patent RU 2616275, 13 April 2017.

37. Vinetsky, Y.P.; Vavilova, E.A.; Chulkin, A.M.; Okunev, O.N.; Sokolova, L.M.; Sinitsyn, A.P.; Chernoglazov, V.M.; Sinitsyna, O.A. A way for production of a complex enzyme preparation (variations) for feed biorefinery and a Penicillium canescens strain (variants). Patent RU 2288267C2, 27 November 2006.

38. Sinitsyn, A.P.; Rozhkova, A.M.; Zorov, I.N.; Bushina, E.V.; Sereda, A.S.; Zverlov, V.V.; Schwartz, V.G. A novel recombinant strain of filamentous fungus Penicillium canescens CS15, a producer of Clostridium thermocellum cellulose, and the producer culturing method. Patent RU 2612158C1, 2 March 2017.

39. Vinetsky, Y.P.; Rozhkova, A.M.; Chulkin, A.M.; Satrutdinov, A.D.; Sinitsyna, O.A.; Fedorova, E.A.; Bekkarevich, A.O.; Okunev, O.N.; Sinitsyn, A.P. Regulatory activity of heterologous gene-activator $x \ln$ of Aspergillus niger in Penicillium canescens. Biochemistry (Moscow) 2009, 74, 882-887. [CrossRef] [PubMed]

40. Volkov, P.V.; Rozhkova, A.M.; Pravilnikov, A.G.; Andrianov, R.M.; Dotsenko, G.S.; Bekkarevich, A.O.; Koshelev, A.V.; Okunev, O.N.; Zorov, I.N.; Sinitsyn, A.P. Production of enzyme preparations on the basis of Penicillium canescens recombinant strains with ability for the hydrolysis of plant materials. Appl. Biochem. Microb. (Mosc.) 2012, 48, 58-64. [CrossRef]

41. Sinitsyna, O.A.; Gusakov, A.V.; Okunev, O.N.; Serebryany, V.A.; Vavilova, E.A.; Vinetsky, Y.P.; Sinitsyn, A.P. Recombinant endo-beta-1,4-xylanase from Penicillium canescens. Biochemistry (Moscow) 2003, 68, 1313-1319. [CrossRef] [PubMed]

42. Sinitsyna, O.A.; Fedorova, E.A.; Semenova, M.V.; Gusakov, A.V.; Sokolova, L.M.; Bubnova, T.M.; Okunev, O.N.; Chulkin, A.M.; Vavilova, E.A.; Vinetsky, Y.P.; et al. Isolation and characterization of extracellular pectinlyase from Penicillium canescnes. Biochemistry (Moscow) 2007, 72, 561-571. [CrossRef]

43. Sinitsyna, O.A.; Fedorova, E.A.; Vakar, I.M.; Kondratieva, E.G.; Rozhkova, A.M.; Sokolova, L.M.; Bubnova, T.M.; Okunev, O.N.; Chulkin, A.M.; Vinetsky, Y.P.; et al. Isolation and characterization of extracellular alpha-galactosidase from Penicillium canescens. Biochemistry (Moscow) 2008, 73, 97-106. [CrossRef]

44. Volkov, P.V.; Sinitsyna, O.A.; Fedorova, E.A.; Rojkova, A.M.; Satrutdinov, A.D.; Zorov, I.N.; Okunev, O.N.; Gusakov, A.V.; Sinitsyn, A.P. Isolation and properties of recombinant inulinases from Aspergillus sp. Biochemistry (Moscow) 2012, 77, 492-501. [CrossRef]

45. Xiang, L.; Wang, Q.; Zhou, Y.; Yin, L.; Zhang, G.; Ma, Y. High-level expression of a ZEN-detoxifying gene by codon optimization and biobrick in Pichia pastoris. Microb. Res. 2016, 93, 48-56. [CrossRef] 
46. Grenier, B.; Loureiro-Bracarense, A.-P.; Leslie, J.F.; Oswald, I.P. Physical and Chemical Methods for Mycotoxin Decontamination in Maize. In Mycotoxin Reduction in Grain Chains; Leslie, J.F., Logrieco, A., Eds.; Wiley-Blackwell: Hoboken, NJ, USA, 2014; pp. 116-129. ISBN 978-0-813-82083-5. [CrossRef]

47. Liu, Y.; Wan, Y.; Zhu, J.; Yu, Z.; Tian, X.; Han, J.; Zhang, Z.; Han, W. Theoretical study on zearalenol compounds binding with wild type zearalenone hydrolase and V153H mutant. Int. J. Mol. Sci. 2018, 19, 2808. [CrossRef]

48. Hao, X.; Chang, X.; Wu, S.; Wu, Z.; Sun, C. Study on the factors to affect the activity of zearalenone degrading enzyme ZLHY6. Sci. Technol. Cereals Oils Foods 2013, 21, 99-101.

49. Juturu, V.; Wu, J.C. Microbial xylanases: Engineering, production and industrial applications. Biotechnol. Adv. 2012, 30, 1219-1227. [CrossRef]

50. Dzhavakhiya, V.; Voinova, T.; Popletaeva, S.; Statsyuk, N.; Limantseva, L.; Shcherbakova, L. Effect of various compounds blocking the colony pigmentation on the aflatoxin B1 production by Aspergillus flavus. Toxins 2016, 8, 313. [CrossRef] [PubMed]

51. Zhemchuzhina, N.; Shcherbakova, L.; Mikityuk, O.; Nazarova, T.; Campbell, B. Extracellular degradation of aflatoxin by certain fungi previously identified as aflatoxin B1 biodestructors. J. Plant Pathol. 2011, 93, 26. [CrossRef]

52. Savitsky, P.; Bray, J.; Cooper, C.D.; Marsden, B.D.; Mahajan, P.; Burgess-Brown, N.A.; Gileadi, O. Highthroughput production of human proteins for crystallization: The SGC experience. J. Struct. Biol. 2010, 172, 3-13. [CrossRef] [PubMed]

53. Aslanidis, C.; de Jong, P.J. Ligation-independent cloning of PCR products (LIC-PCR). Nucleic Acids Res. 1990, 18, 6069-6074. [CrossRef]

54. Smith, B.E. Protein Sequencing Protocols; Humana Press: Totowa, NJ, USA, 1997.

55. Dotsenko, A.S.; Rozhkova, A.M.; Gusakov, A.V. Properties and N-glycosylation of recombinant endoglucanase II from Penicillium verruculosum. Mosc. Univ. Chem. Bull. 2015, 70, 283-286. [CrossRef]

56. Dotsenko, A.S.; Gusakov, A.V.; Volkov, P.V.; Rozhkova, A.M.; Sinitsyn, A.P. N-Linked glycosylation of recombinant cellobiohydrolase I (Cel7A) from Penicillium verruculosum and its effect on the enzyme activity. Biotechnol. Bioeng. 2016, 113, 283-291. [CrossRef]

57. Sanger, F.; Nicklen, S.; Chase, A.R. DNA Sequencing with chain-terminating inhibitors. Proc. Natl. Acad. Sci. USA 1977, 74, 5463-5467. [CrossRef]

58. Aleksenko, A.; Makarova, N.; Nikolaev, I.; Clutterbuck, A. Integrative and replicative transformation of Penicillium canescens with a heterologous nitrate-reductase gene. Curr. Genet. 1995, 28, 474-478. [CrossRef]

59. Shcherbakova, L.; Statsyuk, N.; Mikityuk, O.; Nazarova, T.; Dzhavakhiya, V. Aflatoxin B1 degradation by metabolites of Phoma glomerata PG41 isolated from natural substrate colonized by aflatoxigenic Aspergillus flavus. Jundishapur J. Microbiol. 2015, 8, e24324. [CrossRef]

60. Shcherbakova, L.A.; Nazarova, T.A.; Mikityuk, O.D.; Istomina, E.A.; Odintsova, T.I. An extract purified from the mycelium of a tomato wilt-controlling strain of Fusarium sambucinum can protect wheat against Fusarium and common root rots. Pathogens 2018, 7, 61. [CrossRef]

(C) 2020 by the authors. Licensee MDPI, Basel, Switzerland. This article is an open access article distributed under the terms and conditions of the Creative Commons Attribution (CC BY) license (http://creativecommons.org/licenses/by/4.0/). 